\title{
Networked in or Networked Out? What \\ Can We Learn from Diverse Learners' \\ Experiences of Progressing with and \\ Completing Doctoral Studies?
}

\author{
Maeve O'Regan
}

\section{Introduction}

Discourse on student success has tended to emphasise academic attainment and retention (York et al. 2015). However, influences such as globalisation, increasing diversity of student populations and the potential of digital technologies to support the student experience require redefining and expanding how success is understood in Higher Education Institutions (HEIs) worldwide (York et al. 2015). The current paper is examining student success in the context of a sample of students' experiences of accessing academic and personal support during doctoral candidature.

This article focuses on a preliminary study which investigated if full and parttime doctoral candidates reported differences in terms of access to programme-based information and academic and personal support networks during the doctoral studies.

The current paper explores how HEIs might harness both face-to-face and online resources to enhance access to programme-based and social support to meet the needs of different learners. The findings from this study can provide insights to policymakers and practitioners on supporting a diverse body of students within higher education in Europe, not just within the doctoral process, but at different stages within the Bologna Qualifications Framework.

\section{Context}

Educational reforms in higher education in Europe have been largely influenced by the Bologna Process which has helped to increase transparency, accountability and standardisation within undergraduate and postgraduate programmes within HEIs in

\footnotetext{
M. O’Regan $(\varangle)$

Trinity College Dublin, Dublin, Ireland

e-mail: gallam23@tcd.ie 
Europe (González Geraldo et al. 2011). In a review "The European Higher Education Area (EHEA): 2018 Bologna Process Implementation Report” (European Commission et al. 2018), globalisation, e-learning and increased diversity of student enrolments were identified as significantly influencing higher education policy and practice and the quality of the student experience.

Policy initiatives at a national level, for example, the National Strategy for Higher Education in Ireland for the year 2030 (Department of Education and Skills 2011), have identified the importance of providing flexible, online and distance learning options to support diverse learners needs, including distance and part-time students and learners who are in employment.

Varwell (2018) recommends broadening the scope of student engagement in quality assurance processes which tends to be represented by full-time undergraduate students, to ensure that a more diverse body of student voices are heard, and that online and postgraduate students are included as partners in quality and that student engagement reflects the full experiences of an institutions student profile.

In summary, greater diversity of student populations (e.g. part-time, mature, international and online learners) and changing patterns of access and entry to higher education have presented challenges to policymakers and practitioners to create more flexible entry pathways and modes of study within educational programmes, such as part-time and online learning options.

\title{
3 Access and Progression to Higher Education for Non-traditional Students
}

\begin{abstract}
Lifelong learning is slowly emerging as a new vision for education enabling individuals to continually update their skills to meet the constantly evolving market demand (European Commission et al. 2018, p. 193).
\end{abstract}

Discourse on educational policy and practice has been critiqued as tending to focus on the experience of the traditional, young full-time students in higher education, including learners within the doctoral process. Researchers (Hopwood 2010) recommend exploring the student experience from multifaceted perspectives, such as external personal and social networks, family and employment responsibilities and other time and personal commitments

Traditional access into tertiary education is being challenged by students postponing entry into Higher Education in favouring of entering the workforce or taking a gap year after finishing secondary level education, potentially to capitalise on employment opportunities or as a result of limited financial support to undertake studies (European Commission et al. 2018).

\subsection{International Students}

An international student is defined as a person who has left their country of origin and moved to another country for the purpose of study (OECD 2019). According to 
reports (European Commission et al. 2018), the majority of international students participate in education programmes at postgraduate and doctoral level. International students have reported challenges in accessing research networks and opportunities to disseminate research in English language publications, which is the standard language of publication within academia (Curry and Lillis 2010). The role of research communities has been identified as enhancing academic progression and the doctoral student experience (Pyhältö et al. 2009) however, certain groups of students have been found to experience challenges to accessing research networks. Part-time, international and non-science based (e.g. Arts, Humanities and Social Science (AHSS) students have been found to have less access to research networks than their full-time and science-based peers (Deem and Brehony 2000).

\subsection{Doctoral Candidates}

Doctoral policy is governed by the Salzburg principles (European University Association 2016) which acknowledge the difference between doctoral programmes and other levels of study within the first and second cycles within the Bologna process (European Commission et al., 2018), namely the production of original research and knowledge within an innovative research environment (European University Association 2010). Loxley and Kearns (2018) have found that doctoral qualifications have increasingly become the entry-level requirement to practice across a number of academic and industry settings.

Supporting doctoral candidates is a core strategy within higher education policy in Europe and aligns with goals to develop researchers to foster innovation and generate new knowledge and contribute to academic, economic and social reform (European University Association 2016). There has been an $8 \%$ increase in doctoral holders over the period from 2013 to 2017. There were 276,800 doctoral holders in 2017 across OECD countries.

\subsection{Part-Time Doctoral Candidates}

Literature on the experiences of part-time doctoral is sparse with the body of research focusing on the full-time doctoral student's experience. Although generally overlooked in current research studies (Neumann and Rodwell 2009), part-time doctoral candidates can provide valuable insights on the experience of navigating an academic programme at the highest level of the Bologna qualifications framework despite potentially limited ongoing access to the academic institution during candidature compared to full-timers (Watts 2008).

Age is a factor which influences part-time study and, according to statistics (European Commission et al. 2018), there are over twice as many learners within an older rather than younger age group enrolled in part-time programmes across virtually all European Higher Education Area (EHEA) systems. The changing nature of student demographics has prompted researchers, educators and policymakers to acknowl- 
edge the role of learning support and communication mechanisms beyond the context of learning and socialisation within the classroom-based setting.

\section{Doctoral Research Environments}

Despite the fact that there are now doctoral schools in most EHEA countries, only a quarter of doctoral candidates follow their programme in a doctoral school (European Commission et al. 2018). While doctoral schools can provide structure, guidelines for supervision and quality of provision, at times they can be concentrated within certain programmes or units rather than embedded within doctoral programmes and structures across the university (European University Association 2016). One of the goals of the doctoral process is to create inclusive research environments (European University Association 2010) to promote the generation of original knowledge research by a diverse body of doctoral candidates (European University Association 2016). Researchers have highlighted how research communities of practice can foster inclusiveness and sense of belonging for doctoral candidates (Christensen and Lund 2014). However, doctoral candidates in certain disciplines (e.g. science-based) and enrolled full-time tend to have greater access to research communit

Researchers have identified the attention given predominantly to supporting doctoral candidates in Medicine and STEM (Science, Technology, Engineering and Maths) disciplines and recommend addressing the needs of doctoral candidates in the Social Sciences (European University Institute 2017). The development of coherent and transparent admissions policies that recognises the needs of individual learners and different dimensions of research talent (European University Association 2016) can help support doctoral candidates in making the transition from dependent to independent researcher (Lovitts 2008).

\section{Defining Student Success-The Role of Socialisation and Academic Networks}

The term student success has been described as an ambiguous and multifaceted concept, primarily based around measures of student academic attainment and retention (York et al. 2015). Academic performance and retention can be useful ways to evaluate student success. However, levels of integration and quality of interaction between the student and the academic environment, faculty and peers can also influence student performance and decisions to stay or drop out of the institution (Angulo-Ruiz and Pergelova 2013).

Socialisation of the student into the academic institution has been identified as influencing the quality of the doctoral student experience and academic performance (Jones 2013; Weidman and Stein 2003). The importance of the classroom has been highlighted as providing the opportunity and setting for students to engage in learning 
activities and meet academic staff and peers, particularly for students who work or attend courses on a part-time basis (Tinto 2012).

Leander et al. (2010) recommend that researchers move beyond the tendency for discourse within educational research to focus on the role of the school or classroom as a bounded system to explore the role of technologies in transferring knowledge and information and connecting people across time, space and place, for example, across both local and global settings.

\subsection{Face-to-face Support Versus Digital Technologies and Online Resources}

The value of online and distance learning options is gradually being recognised as providing a way to meet the needs of an increasingly diverse body of students participating in higher education worldwide (Leander et al. 2010). A review of progress with the implementation of the Bologna Process reforms (European Commission et al. 2018) has identified the potential of digital technologies in enhancing the transparency of learning outcomes and course workload, providing flexible learning paths and meeting the needs of under-represented groups, such as distance and part-time students.

However, results from the Postgraduate Researcher Experience Survey (PRES) UK suggests that students prefer face-to-face rather than online communication and feedback (Slight 2017). Researchers (González Geraldo et al. 2011) note that while technologies such as wikis, podcasts, blogs and emails can support learning, digital media should complement rather than replace face-to-face interaction and communication. Berry (2017) recommends further research into identifying social structures to support online students and suggests that universities extend existing technology and online support to enhance learning and social opportunities for online and distance-based learners.

\section{Introduction to the Current Research Study}

The current research study is an ongoing Ph.D. project (2016-to date) comprising of two phases, a preliminary exploratory stage and a main study. The overall aim of the research is to explore how a sample of part-time doctoral candidates experienced access to academic and personal support networks within the academic institution during doctoral candidature. The research also explores if part-time doctoral candidates demonstrated agency to influence academic progression and completion of studies, for example seeking help for others, within and outside the academic institution via face-to-face and online communication mechanisms. The findings from a preliminary stage in the research are presented here. This phase of the research highlights similarities and differences, predominately between full and part-time doctoral candidates (who participated in the study) and draws some conclusions on students' 
experiences of accessing face-to-face and online doctoral programme information and support networks.

\subsection{Preliminary Phase of the Research (Full-time and Part-Time Doctoral Candidates)}

The initial stage of the study (2017-2018) was conducted to investigate if there was merit in exploring the part-time learner's experience of progressing through studies as significantly different to the full-time candidate's journey in terms of access to academic and social support networks within the academic institution during doctoral candidature.

This phase of the research was conducted in a single research-intensive university in Ireland, and participants included full and part-time doctoral candidates at different stages of the research process and from different disciplines. Based on the results from the preliminary study, the research tools (questionnaire and semi-structured interview process) were developed and refined to explore the experiences of candidates who had completed doctoral studies on a part-time basis within the university sector in Ireland.

The main phase of the research is currently in progress, and initial perspectives on this phase of the study will be briefly discussed at the end of this paper.

\subsubsection{Conceptual Framework and Research Design of Study}

The research design for the (preliminary and main) study draws on Actor-Network Theory (Latour 2005) and theories of Agency. Actor-Network Theory acknowledges the role of non-human (Latour 2005; Law 1992; Sayes 2014) as well as human sources of information and knowledge transfer, for example, via documents and technologybased communications. The role of distributed actors and networks is addressed by other researchers, for example (Hopwood 2010) in terms of the multifaceted nature of the doctoral students' world, social networks and sources of knowledge (e.g. academic and personal contacts, documents and books).

According to Nespor (2002), some actors, for example students, are often relegated and decontextualized rather than viewed as agents of change, which is assumed to take place within the institutional context. González Geraldo et al. (2011) highlight the unique opportunity that the European Higher Education Area (EHEA) has to improve higher education systems in Europe and recommend ensuring teachers and students are included in consultations on reforming education and promoting student success. The role of the student in demonstrating agency such as seeking support and taking action to progress with studies is identified as a key aspect of the student experience (McAlpine et al. 2012). 


\subsubsection{Theories of Agency}

The role of individuals in shaping and being shaped by their social context is developed by Archer (2003) who suggests that the individual constitutes a self who can interact socially and act reflexively to shape their external circumstances and reality. The ideas proposed (Archer 2003) combine both psychological (agency) and social (structure and culture) influences on human behaviour and advancement.

Her theories seek to redress this imbalance by exploring how cultural and structural factors are perceived by individuals, and, in turn, responded to in terms of personal agency. Thereby, addressing deficits identified in other learning theories which have been critiqued as either too focused on the individual or the environment (Mälkki 2010) without looking at the dynamic interaction between both influences. Archer (2003) states that individuals are dynamic agents in their own lives, are not passive and can respond reflexively to shape their own lives and personal projects based on an evaluation of the constraints and enablers experienced through interaction with the social (structural and cultural) world.

Student agency, motivation and personal resourcefulness have been identified as key to persistence and completion of the Ph.D. (McAlpine et al. 2012). Kahn (2014) identified the importance of reflexivity and responsibility and recommended that the student act as an agent mediating internal and social aspects of the learning environment.

\subsubsection{Rationale for Conceptual and Methodological Framework}

The combination of Actor-Network Theory and Theories of Agency provided a way for the researcher to explore aspects of the external (e.g. academic environment and social interaction) and individual (student agency and actions) influences that can shape a student's journey. The inclusion of the online and document-based aspects of information as well as human sources of communication provided a way to explore multifaceted dimensions of the student's world across time, space and place rather than just within the context of face-to-face interaction, for example, in the physical campus or academic environment.

\section{Methodology}

A mixed methods research design was used in this study. The researcher developed a questionnaire, influenced by Actor-Network Theory to explore participants' experiences of accessing face-to-face and online doctoral programme information and support from the academic institution during candidature. The interview process was influenced by socio-psychological theories of agency (Archer, Hopwood, McAlpine) which accept that the person is part of a social system rather than just a single individual entity and finds a way to look at social and psychological (external and internal aspects of the students) world which influence academic progression and 
quality of the student experience. The interview process sought information on any enablers or barriers participants had experienced (environmental or personal) during the doctoral process and explored if participants demonstrated agency, for example, drawing on their own resources or help from others to progress with studies.

Participants for both the preliminary and (ongoing) main research phase were recruited via snowballing sampling methods (Creswell 2012). This involved the researcher asking respondents to pass on details of the project to their own networks to recruit a wide sample of participants beyond the researcher's own personal contacts.

The questionnaire was analysed using descriptive statistics (Pallant 2005), and the interview responses were examined using thematic analysis (Braun and Clarke 2006) to identify common and individual themes within and across the participants' responses.

Eighteen doctoral candidates (11 full-time and 7 part-time) from a single university in Ireland took part in the preliminary research phase. Four additional participants were interviewed (academic staff and postgraduate representatives) to provide context and an additional perspective on support for doctoral learners. Of the 18 doctoral candidates who participated in this phase of the study, 15 were from Arts, Humanities and Social Science (AHSS) and three were studying within the Health Sciences (HS). There were 15 female and 3 male student participants within an age range of $25-55+$ on starting their doctoral studies. Two-thirds of participants (12) were over 35 years of age on starting their studies. Participants include early, mid-stage, completing and completed doctoral candidates.

As previous research studies have highlighted the potential disparity between science and non-science-based students in terms of opportunity to participate in research network, the researcher was particularly interested in the experiences of AHSS doctoral candidates. However, as this was an exploratory phase of the study, the researcher endeavoured to recruit participants from as broad a sample, from as diverse a range of disciplinary fields as possible. Participant recruitment will be addressed in more detail in this paper.

\section{Limitations}

The preliminary research was conducted in a single research-intensive university in Ireland which may lead to a potential bias in terms of the findings, which may reflect specific cultural and structural aspects of the institution, not generalisable to other universities. Based on the findings from initial research, the main phase of the study (currently in progress) will expand the study to include part-time doctoral candidates (who are the main focus of enquiry in this Ph.D. study) who completed studies within other universities in Ireland.

The main study will focus on the experience of completed part-time doctoral candidates as the findings from the preliminary study showed that completed or completing candidates (both full and part-time) had a greater sense of what worked and what didn't (retrospectively) at each of the doctoral processes than those who 
were at early or mid-stages of the research journey. Researchers recommend further studies into the experiences of completed doctoral students (Devos et al. 2017).

The majority, fifteen of the eighteen participants, were studying in an Arts, Humanities and Social Science field. While the aim of the study was to explore the experiences of non-science based doctoral candidates, the low number of participants from Health Sciences (3) and lack of representation of participants from the sciencebased disciplines may have influenced the findings from the study. Further studies could explore in more depth differences experienced by students from various disciplines (science and non-science based) in terms of accessing doctoral programme information and support networks during candidature.

Four (full-time) international (EU and non-EU) doctoral students took part in the study. Although the goal of the study was to look more broadly at full and part-time doctoral candidates' experiences, rather than differences between domestic and international students, responses from international learners provided valuable insights into the experience of non-traditional learners. Themes such as difficulties accessing academic and peer-networks, lack of familiarity with the research culture and barriers to accessing doctoral programme information (face-to-face and online) were highlighted particularly by non-traditional learners (e.g. part-time and international students.). These themes require further exploration (beyond the scope of the current research) with a larger sample of participants.

An interview conducted with an academic staff member in a science-based discipline who participated in the study indicated that there tended to be very few part-time doctoral candidates in the Sciences (or Health Sciences) due to the often team-based structures of the research environment and nature of funding (e.g. student research is often financed by an external research agency.) The focus on participants from AHSS may also have led to a bias towards higher levels of female than male participants. According to statistical data (Higher Education Authority 2018a, b), there are more females than males enrolled both full and part-time in AHSS disciplines at doctoral level in Ireland.

\section{Key Findings}

The findings indicated that there are similarities and differences between individual students in terms of enablers and barriers to accessing face-to-face communities and research networks within the academic institution. However, full-time candidates tended to have greater access to academic and personal support networks within the academic institution than their part-time peers (O'Regan 2018).

\subsection{Employment}

$70 \%$ of both full and part-time participants reported undertaking employment while studying. Part-time participants tended to be in full-time employment prior to starting 
the Ph.D. and often continued working full-time while undertaking studies. Limited financial support for part-time doctoral candidates, as well as the need to meet personal financial commitments (e.g. mortgage, family and living expenses), were cited as reasons for enrolling on a Ph.D. on a part-time basis.

The 6 years part-time Ph.D. process is a challenge, but it would have been unrealistic to change to full-time. It wouldn't have made sense financially in terms of my other commitments (quote from part-time participant.)

Full-time participants tended to work on a short-term and casual basis during the Ph.D.. The financial commitments associated with undertaking doctoral studies, including the need to earn income to supplement funding doctoral scholarships, were cited by full-time participants as the main reason for working while studying. The high cost of living and restrictive budget for travel and living expenses was cited as a source of stress, particularly by full-time learners

I am barely keeping my head above water (quote from full-time participant)

\subsection{Access to the Academic Institution}

In line with existing research findings, part-time respondents tended to work on a continuous and often full-time basis while studying. For some part-time learners, this presented challenges in terms of accessing supports, training, seminars and peer networks from the academic institution during the predominantly 9 am-5 pm working day.

\subsection{Infrastructure and Links Between Administrative and Academic Departments}

Both full and part-time respondents reported a lack of clarity on how administrative, financial and academic functions related to each other. Participants reported seeking support, often on a face-to-face basis, usually from supervisors to follow up on queries regarding the status of research funding applications, fee payments and expenses claims. Lack of transparency of systems and difficulty navigating, or sourcing information online was cited by participants as a barrier to accessing information and created a dependency on informal networks of academic staff and personal contacts familiar with or working in the university system. 


\subsection{Face-to-face Versus Online Information Sources and Support Networks}

In general, both full and part-time participants tended to access doctoral programme and process information informally, "over a cup of coffee" or through "knocking on doors within the academic department" or through a small network of personal contacts within the university. Participants tended not to refer to more formal web sources or wider formal or official sources of information from the university. As one participant commented on the formal information relevant to the doctoral process available in document-based and online form was:

It's there somewhere -but it's hard to find (quote from full-time participant).

The reliance on face-to-face informal networks and a dependence on "word of mouth" to source information could potentially result in doctoral students accessing inaccurate or incomplete information, or missing out partially or completely on information, support and training relevant to doctoral progression and quality of experience.

\subsection{Access to Academic Staff and Peer Networks}

The tendency to depend on face-to-face information from a small sample of sources also acted as a barrier in terms of accessing academic information and social networks for some participants. These included participants who were new to the institution, part-time and non-traditional learners seemed to have greater difficulty navigating the doctoral process and taking ownership of their own success and progression than learners who were full-time or had completed a previous qualification in the university.

I found it hard to know who to go to for academic information and personal support when experiencing difficulties with the Ph.D.. My fellow Ph.D. students and grown up children were invaluable in helping me to navigate the system based on their own experiences of Higher Education (quote from full-time participant, new to the institution and mature learner.)

Part-timers tended to know other part-timers, and due to often limited shared time to interact within the academic institution, part-time networks often disbanded over time. Accessing a social network of peers was often dependent on a fellow Ph.D. student (usually full-time and located within a shared study space in the university) acting as a catalyst and encouraging people to mix socially and go for coffee. Full-time participants also reported the importance of peer groups which was often dependent on working in a shared space that encouraged interaction with others.

You could be lucky or unlucky with your peer group or what type of study space you occupied in terms of meeting others and mixing with fellow Ph.D. students (quote from a full-time international participant). 


\subsection{Access to External Research and Professional Networks (Face-to-face and Online)}

Students who had difficulty accessing academic information and support networks from formal communication and information channels (face-to-face and online) often demonstrated agency in accessing and developing their own face-to-face and online networks outside the university. International (who tend to be full-time) and parttime doctoral candidates who had research careers or worked in the higher education sector (for example, in their own country) prior to starting the Ph.D. cited the benefits of having academic and personal colleagues to seek support from. They tended to draw on support from these colleagues (for example, via email) rather than seeking face-to-face and online support from the academic institution. A supportive workenvironment, line manager and organisational culture of supporting employees who are undertaking doctoral studies has been identified as a motivating influence on parttime doctoral candidates who are balancing studies with employment. ( $\mathrm{O}$ ' Regan 2019).

My previous experience as a lecturer and researcher helped with my expectations [of the Ph.D.] (quote from full-time international participant).

Talking to colleagues in my home country helps. Most studied in other countries, so they know what it's like. My friends and family provide the support I need (quote from full-time interactional Ph.D. participant.).

\subsection{Access to Online Doctoral Forums and Discussion Boards}

Participants, in particular part-timers, discussed referring to external online Ph.D. forums, discussion boards and thesis writing support groups in order to progress with doctoral studies. These findings suggest that there is a network of dynamic communication and support being developed in terms of face-to-face and online interaction between a broad community of $\mathrm{Ph} . \mathrm{D}$. learners which is taking place independently of the formal infrastructure and communication networks operating within the academic institution.

I receive information on the Ph.D. from my supervisor and from people I know in other universities and my online life (quote from part-time participant).

I'm part-time and far away. Even if I was full-time I'd find my "tribe" online outside of the $\mathrm{Ph} . \mathrm{D}$. community within the academic institution (quote from part-time participant.). 


\subsection{Agency and Help-Seeking Behaviour}

Both full and part-time participants demonstrated agency and help-seeking behaviour to progress with doctoral studies, such as using strategies to manage time, seek contact with supervisors and access training, information and support to progress with doctoral studies where possible. Full-time candidates tended to benefit from frequent and ongoing access to the campus environment to participate in research training and activities and develop research and personal support networks with peers and supervisors.

Part-time candidates reported more limited access to research networks and activities within the academic institution but demonstrated agency by using time on campus as effectively as possible. This included use of resources, such as the Library, attending training and events, seeking guidance from supervisors and building up peer networks with other part-time students, and where possible full-time candidates.

I tended to be as self-directed as possible, focusing on the academic rather than the social [Ph.D.] process, except for conferences and the monthly Ph.D. seminars- which I attended (quote from part-time participant).

\subsection{Isolation}

The issue of isolation and loneliness was mentioned by some respondents (both full and part-time)_-despite being physically on campus often had no one else to talk to. Some participants commented that were not naturally extroverted, so felt they were at a disadvantage in terms of access to information and academic and personal support networks. Participants mentioned resilience as important in terms of needing to manage self, motivation and expectations and keep working often in the absence of much formal doctoral structure or social support to guide them. The theme of "insiders" and outsiders" was discussed. Respondents who described themselves as outsiders tended to be first-generation Ph.D. students (first in their family to undertake doctoral studies), part-time and some international students and those without the previous academic experiences within the university.

If you want anything here you need to be an extrovert and I'm not (quote from part-time participant).

\section{Discussion and Conclusions}

In general, full-time participants found it easier to access academic and social support within the academic institution than their part-time peers. The tendency for participants to seek information and support relating to the doctoral process on a face-toface basis from collegial networks comprising of supervisors and peers rather than 
referring to college or departmental website was reported by both full and part-time participants. Dependence on access to informal face-to-face networks within the academic institution may be a barrier to accessing accurate and timely information for students.

The findings from this preliminary stage research study illustrate the multifaceted lives of a diverse body of doctoral students, including full-time, part-time and international learners. Access to supportive individuals, resources, research networks and support services within the academic institution provided students with opportunities for academic, personal and professional development. The sense of community and well-being that the campus environment provided, especially a place (e.g. desk) within a community of fellow doctoral students and the time and space to engage in different activities for personal and professional development was highly valued by full-time participants.

Results from this research study highlight the importance of access to the physical and research environment of the academic institution providing the time, place and space for students to engage in research activities and access supportive networks and opportunities for personal and professional development.

The findings from the study indicate the need to provide doctoral programme information and social support for students, either with limited access to the academic institution (potentially due to managing other employment and family roles in tandem with studying) or with potential barriers to accessing social support on campus. The results suggest that "one size does not fit all”, and different students can encounter various barriers and enablers to accessing programme-based information and participating in academic and personal networks during doctoral candidature.

In conclusion, the findings of this study support existing research on the role of socialisation of doctoral students into the academic norms and collegial culture of the faculty and academic institution as influencing doctoral student progression and quality of experience. The challenge for academic institutions may be to provide an equivalent experience for diverse learners who may have more limited physical (e.g. part-time) and social access (e.g., part-time and international learners) to the HEI environment.

This may lead to HEIs developing a combination of face-to-face and online learning supports to cater for students with various personal, academic, situational and lifestyle circumstances which can impact on student success, both in terms of academic progression and completion and quality of the student experience.

\section{Recommendations}

The recommendations given by participants to enhance doctoral programme information and personal support are summarised as follows:

- Web-based and online support to compliment face-to-face learning opportunities: all learners, but in particular students with limited access to the campus 
environment would benefit from greater access to online information and guidelines to help mediate, manage and navigate the doctoral process. Researchers recommend exploring the role of online communication and digital technologies to complement face-to-face interaction and promote socialisation and interaction for "hard to reach" students (e.g. part-time, commuting or distance learners).

- Transparency and standardisation of expected outcomes and forms of assessment across each stage of the doctoral process: Examples included initial and annual progress reports, requirements and available offerings for students in terms of training and credit bearing modules, record-keeping in relation to the student's progress and guidelines on mid-stage and final Viva/Thesis assessment and submission process.

- Training for supervisors (in particular new supervisors): on institutional procedures, milestones and forms of assessment during the doctoral process as well as information on the different administrative, financial, academic and student supports available to the student during the doctoral journey.

- Promote s sense of community and a positive research culture within departments and across the academic institution: For example, a "meet and greet" where new doctoral students can meet academic and administrative staff and other postgraduate and doctoral students to find out about the different research activities and interests being undertaken by colleagues.

- Transparency and coherence between administrative, financial and academic functions (face-to-face and online) to allow students to access information and take ownership of the doctoral process without depending on informal personal networks (e.g. supervisor or peers for information and support). For example, registration process, claiming expenses and funding (especially when the student funding is coming from an external research agency), appeals process and formal guidelines and expectations of the student, supervisor and the academic institution during the Ph.D..

\section{References}

Angulo-Ruiz, L. F., \& Pergelova, A. (2013). The student retention puzzle revisited: The role of institutional image. Journal of Nonprofit \& Public Sector Marketing, 25(4), 334-353. https://doi. org/10.1080/10495142.2013.830545

Archer, M. A. (2003). Structure, agency and the internal conversation. Cambridge, UK: Cambridge University Press.

Berry, S. (2017). Student support network in online doctoral programs: Exploring nested communities. International Journal of Doctoral Studies, 12, 33.

Braun, V., \& Clarke, V. (2006). Using thematic analysis in psychology. Qualitative Research in Psychology, 3(2), 77-101. https://doi.org/10.1191/1478088706qp063oa

Christensen, M. K., \& Lund, O. (2014). Doctoral education in a successful ecological niche: A qualitative exploratory case study of the relationship between the microclimate and doctoral students' learning to become a researcher. International Journal of Higher Education, 3(3), 103113. https://doi.org/10.5430/ijhe.v3n3p103 
Creswell, J. W. (2012). Educational research planning, conducting and evaluating quantitative and qualitative research (4th ed.). Boston: Pearson.

Curry, M. J., \& Lillis, T. M. (2010). Academic research networks: Accessing resources for englishmedium publishing. English for Specific Purposes, 29(4), 281-295. https://doi.org/10.1016/j. esp. 2010.06 .002

Deem, R., \& Brehony, K. J. (2000). Doctoral students' access to research cultures-are some more unequal than others? Studies in Higher Education, 25(2), 149-165. https://doi.org/10.1080/ 713696138

Department of Education and Skills. (2011). National strategy for higher education 2030: Report from the strategy group. Dublin, Ireland: Department of Education and Skills Retrieved from https://www.education.ie/en/Publications/Policy-Reports/National-Strategy-for-HigherEducation-2030.pdf.

Devos, C., Boudrenghien, G., Van der Linden, N., Azzi, A., Frenay, M., Galand, B., \& Klein, O. (2017). Doctoral students' experiences leading to completion or attrition: A matter of sense, progress and distress. European Journal of Psychology of Education, 32(1), 61.

European Commission, EACEA, \& Eurydice. (2018). The European Higher Education Area in 2018: Bologna Process implementation report. Retrieved from Luxembourg: (http://ec.europa. eu/eurydice).

European University Association. (2010). Salzburg II recommendations: European universities' acheivements since 2005 in implementing the Salzburg principles. Retrieved from Brussels: http://www.eua.be/

European University Association. (2016). Doctoral education - taking Salzburg forward: Implementation and new challenges. Retrieved from Brussels: www.eua.be

European University Institute. (2017). Reforming the doctorate in social sciences: A report on good practices.

González Geraldo, J., Trevitt, C., \& Carter, S. (2011). Realising pedagogical potential of the Bologna process third cycle. Journal of Technology and Science Education, 1(2), 16-24. https://doi.org/ 10.3926/jotse.2011.22

Higher Education Authority. (2018a). Full-time postgraduate doctorate enrolments in all HEA funded institutions by field of study (ISCED) at 1 March 2017. Retrieved from Dublin: http:// www.statistics-archives

Higher Education Authority. (2018b). Part-time postgraduate doctorate enrolments in all HEA funded institutions by field of study (ISCED) at 1 March 2017. Retrieved from Dublin: http:// www.statistics-archives

Hopwood, N. (2010). A sociocultural view of doctoral students' relationships and agency. Studies in Continuing Education, 32(2), 103-117. https://doi.org/10.1080/0158037x.2010.487482

Jones, M. (2013). Issues in doctoral studies-forty years of journal discussion: Where have we been and where are we going? International Journal of Doctoral Studies, 8, 83-104.

Kahn, P. E. (2014). Theorising student engagement in higher education. British Educational Research Journal, 40(6), 1005-1018. https://doi.org/10.1002/berj.3121

Latour, B. (2005). Reassembling the Social: An Introduction to Actor Network Theory. Oxford: Oxford University Press.

Law, J. (1992). Notes on the theory of the actor-network: Ordering, strategy, and heterogeneity. Systems Practice, 5(4), 379-393. https://doi.org/10.1007/BF01059830

Leander, K. M., Phillips, N. C., Taylor, K. H., Nespor, J., \& Lewis, C. (2010). The changing social spaces of learning: Mapping new mobilities. Review of Research in Education, 329-394.

Lovitts, B. E. (2008). Transition to independent research: Who makes it, who doesn't and why. The Journal of Higher Education, 39(3), 296-325.

Loxley, A., \& Kearns, M. (2018). Finding a purpose for the doctorate? A view from the supervisors. Studies in Higher Education, 43(5), 826-840. https://doi.org/10.1080/03075079.2018.1438096

Mälkki, K. (2010). Building on Mezirow's theory of transformative learning: Theorizing and challenge to reflection. Journal of Transformative Education, 8(1), 42-62. 
McAlpine, L., Paulson, J., Gonsalves, A., \& Jazvac-Martek, M. (2012). "Untold” doctoral stories: Can we move beyond cultural narratives of neglect? Higher Education Research and Development, 31(4), 511-523.

Nespor, J. (2002). Networks and contexts of reform. Journal of Educational Change, 3, 365-382.

Neumann, R., \& Rodwell, J. (2009). The 'invisible' part-time research students: A case study of satisfaction and completion. Studies in Higher Education, 34(1), 55-68. https://doi.org/10.1080/ 03075070802601960

O' Regan, M. (2019). How employers can support part-time learners in the workplace: lessons learned from the experiences of completed part-time $\mathrm{PhD}$ graduates in the university sector in Ireland. OP Matters (Vol. 43, pp. 17-18). Leicester: UK: British Psychological Society.

O'Regan, M. (2018). The PhD student's journey: Exploring how interaction with the academic environment informs part-time doctoral student's agency and understanding of the $\mathrm{PhD}$ process. Paper presented at the Excellence through Diversity: Doctoral Education in a Globalised World:11th EUA-CDE Annual Meeting, University of Ljubljana, Ljubljana, Slovenia.

OECD. (2019). Education at a Glance 2019: OECD indicators. Retrieved from Paris: https://read. oecd-ilibrary.org/education/education-at-a-glance-2019_f8d7880d-en\#page1

Pallant, J. (2005). SPSS survival guide- survival manual: A step by step guide to data analysis using SPSS version 12. Berkshire, UK: Open University Press.

Pyhältö, K., Stubb, J., \& Lonka, K. (2009). Developing scholarly communities as learning environments for doctoral students. International Journal for Academic Development, 14(3), 221-232. https://doi.org/10.1080/13601440903106551

Sayes, E. (2014). Actor-Network Theory and methodology: Just what does it mean to say that nonhumans have agency? Social Studies of Science, 44(1), 134-139.

Slight, C. (2017). Postgraduate Research Experience Survey (PRES) report 2017. Retrieved from https://www.heacademy.ac.uk/knowledge-hub/postgraduate-research-experience-surveyreport-2017

Tinto, V. (2012). Enhancing student success: Taking the classroom success seriously. The International Journal of the First Year in Higher Education, 3(1), 1-8. https://doi.org/10.5204/intjfyhe. v2i1.119

Varwell, S. (2018). Engaging diversely: How online students, postgraduates and others can (and should!) be full partners in quality. Paper presented at the 13th European Quality Assurance Forum Broadening the scope of QA, Vienna University.

Watts, J. H. (2008). Challenges of supervising part-time phd students: Towards studentcentred practice. Teaching in Higher Education, 13(3), 369-373. https://doi.org/10.1080/ 13562510802045402

Weidman, J. C., \& Stein, E. L. (2003). Socialization of doctoral students to academic norms. Research in Higher Education, 44(6), 641-656.

York, T. T., Gibson, C., \& Rankin, S. (2015). Defining and measuring academic success. Practical Assessment, Research \& Evaluation, 20(5), 1-20.

Open Access This chapter is licensed under the terms of the Creative Commons Attribution 4.0 International License (http://creativecommons.org/licenses/by/4.0/), which permits use, sharing, adaptation, distribution and reproduction in any medium or format, as long as you give appropriate credit to the original author(s) and the source, provide a link to the Creative Commons license and indicate if changes were made.

The images or other third party material in this chapter are included in the chapter's Creative Commons license, unless indicated otherwise in a credit line to the material. If material is not included in the chapter's Creative Commons license and your intended use is not permitted by statutory regulation or exceeds the permitted use, you will need to obtain permission directly from the copyright holder. 